\title{
Associated postural adjustments in Parkinson's disease
}

\author{
J P R DICK, J C ROTHWELL, A BERARDELLI, P D THOMPSON, M GIOUX, \\ R BENECKE, B L DAY, C D MARSDEN
}

From the MRC Movement Disorders Research Group, University Department of Neurology, and Parkinson's Disease Society Research Centre, Institute of Psychiatry \& King's College Hospital Medical School, London, $U K$

SUMMARY Postural activity in muscles of the back and legs associated with voluntary forward elevation of the arm at the shoulder with the subject standing was examined in 14 patients with Parkinson's disease and nine normal individuals. The time of onset of EMG activity in each of the postural muscles, relative to the onset of activity in the prime mover, was the same for both patient and normal groups and did not depend on load. The amplitude of the EMG bursts and their frequency of occurrence, was less in patients off drug treatment and immobile, than when mobile on therapy. We conclude that the timing of associated postural adjustments is normal in Parkinson's disease, although their size may be decreased.

Patients with Parkinson's disease lose their balance more easily and fall over more frequently than do normal subjects. However, it is not known to what extent such postural instability reflects deficits in the "feedforward" (or programmed) adjustments of posture which precede activation of the prime mover $^{1}$ or in "feedback" (or reflex) mechanisms of compensation. There is some evidence that feedback mechanisms may be compromised in Parkinson's disease. Traub et $a l^{2}$ found that anticipatory postural reflexes in leg muscles, produced by small, unexpected, displacements of the arm, were smaller in patients with Parkinson's disease than in normal controls. However, although there was a tendency for the patients who were more severely affected clinically to have the smallest postural reflexes, there were a number of very unstable patients whose postural reflexes were relatively normal. The conclusion was that although impairment of these reflexes may contribute to postural instability, there must be other factors which contribute to the imbalance of patients with Parkinson's disease.

Previous reports of feedforward responses in Parkinson's disease ${ }^{3}$ have suggested an abnormality of the timing of postural EMG bursts relative to the

Address for reprint requests: Professor C D Marsden, Department of Neurology, Institute of Psychiatry, De Crespigny Park, London SE5 8AF, UK.

Received 4 January 1986. Accepted 1 March 1986 prime mover. In this paper, we have examined the feedforward adjustments in leg and trunk muscles which accompany and precede voluntary movement of the arm in a freely-standing subject. This activity anticipates and reduces body sway produced by the voluntary movement in normal subjects. ${ }^{1457}$ It usually occurs before the onset of EMG activity in the prime mover and is thought to be part of a preformed package of instructions sent to postural muscles in association with activation of the prime mover. ${ }^{7}$ Our results differ from those of Bazalgette et $a l^{36}$ who found that in Parkinson's disease postural EMG activity occurred after the prime mover.

\section{Methods}

\section{(A) Patients (table 1)}

Fourteen non-demented and consenting patients aged $55 \cdot 7$ \pm 13 years (mean $\pm S D$; range $29-76$ years) with idiopathic Parkinson's disease and nine consenting control subjects aged $49 \cdot 3 \pm 15$ years (mean $\pm S D$, range 33-67 years) were studied using the same paradigm.

Patients were chosen if their motor disability was predominantly of the akinetic type and if they showed little tremor. All patients had moderate to severe disease, showed severe immobility in the untreated state and demonstrated either freezing, festination or retropulsion. Thirteen of the 14 had impaired balance when untreated but not all suffered from falls (table 1).

All fourteen patients were studied at least 12 hours after their last dose of anti-Parkinsonian medication when immobile and in the OFF condition. Ten of these patients were 
Table 1 Clinical features and treatment of the patients with Parkinson's disease

\begin{tabular}{|c|c|c|c|c|c|c|c|}
\hline $\begin{array}{l}\text { Name } \\
\end{array}$ & Age $y r$ & $\begin{array}{l}\text { Disease } \\
\text { duration yr }\end{array}$ & Drugs§ & Akinesia\| & Rigidity\| & Tremor\| & $\begin{array}{l}\text { Postural } \\
\text { reflexes }\end{array}$ \\
\hline $\begin{array}{l}\text { WW* } \\
\text { DO } \\
\text { BU } \\
\text { JMc } \\
\text { AR } \\
\text { WR† } \\
\text { IS* } \\
\text { MM } \\
\text { PE } \\
\text { AG } \\
\text { RC† } \\
\text { MC* } \\
\text { JB* } \\
\text { EG } \ddagger\end{array}$ & $\begin{array}{l}76 \\
29 \\
70 \\
61 \\
56 \\
36 \\
52 \\
56 \\
48 \\
69 \\
54 \\
60 \\
52 \\
62\end{array}$ & $\begin{array}{r}3 \\
12 \\
8 \\
5 \\
7 \\
5 \\
10 \\
8 \\
10 \\
22 \\
19 \\
14 \\
14 \\
20\end{array}$ & $\begin{array}{l}\text { S } 1254 \text { hourly } \\
\text { S } 1102 \text { hourly } \\
\text { S } 1103 \text { hourly } \\
\text { S } 1254 \text { hourly } \\
\text { S } 1252 \text { hourly** } \\
\text { S } 2203 \text { hourly } \\
\text { S } 1102 \text { hourly } \\
\text { Artane amantadine } \\
\text { S } 1102 \text { hourly } \\
\text { S } 1102 \text { hourly** } \\
\text { S } 2753 \text { hourly } \\
\text { S } 2752 \text { hourly** } \\
\text { S } 2753 \text { hourly** } \\
\text { S } 1102 \text { hourly** }\end{array}$ & $\begin{array}{l}++ \\
++ \\
++ \\
++ \\
+++ \\
++ \\
++ \\
++ \\
+++ \\
+++ \\
+++ \\
+++ \\
+++ \\
+++\end{array}$ & $\begin{array}{l}++ \\
+ \\
+ \\
+ \\
++ \\
+ \\
+ \\
++ \\
+++ \\
+++ \\
++ \\
+++ \\
++ \\
+++\end{array}$ & $\begin{array}{l}0 \\
++ \\
0 \\
+ \\
0 \\
+++ \\
0 \\
0 \\
+ \\
+ \\
0 \\
+ \\
+++ \\
+\end{array}$ & $\begin{array}{l}0 \\
+ \\
+ \\
+ \\
+ \\
+ \\
+ \\
+ \\
++ \\
++ \\
++ \\
++ \\
++t \\
++t\end{array}$ \\
\hline
\end{tabular}

*not studied ON therapy, tnot studied at $12 \mathrm{~N}$, ‡not studied at $24 \mathrm{~N}, \S \mathrm{S}=$ Sinemet therapy, ${ }^{* *}=$ also taking bromocriptine, pergolide or artane.

$\|$ Akinesia, rigidity and tremor were scored clinically as, 0 none; + mild; ++ moderate; +++ severe

ๆPostural reflexes were scored clinically as, 0 normal postural responses; + abnormal postural responses, no falls; ++ abnormal postural responses, occasional falls; +++ abnormal postural responses, many falls

studied both when relatively immobile and OFF treatment, and immediately after being rendered mobile by their normal morning dose of levodopa.

\section{(B) Experimental design}

Subjects stood erect and unsupported with their feet together and their arms hanging loosely by their sides. With their right hand they held a strap, which was connected via a light chain to a pulley on the shaft of a brushless torque motor (Printed Motors Type G16M) situated directly behind them at wrist height. They were instructed to keep the strap taut and to pull it forwards $15-20 \mathrm{~cm}$ as rapidly as possible, in their own time, against a force offered by the motor $(12 \mathrm{~N}$ or $24 \mathrm{~N})$. At the start of the movement the pulley rested on an end stop so the subject did not feel the opposing load until after the arm had moved. The arm was kept extended at the elbow and the movement was produced by forward elevation of the arm at the shoulder. Movements were rejected if they were accomplished by elbow flexion. The position of the arm was monitored by a potentiometer attached to the spindle of the torque motor. A velocity signal was electronically derived from the position signal. EMG activity was recorded from surface electrodes over anterior deltoid, posterior deltoid, erector spinae (ES) at the level of $\mathrm{Ll}$, biceps femoris in its mid portion (HAMS), tibialis anterior (TA) and triceps surae (TS), from its lower half. Signals were passed through a Devices 3120 amplifier (with high and low pass filters set respectively $3 \mathrm{~dB}$ down at $80 \mathrm{~Hz}$ and $2.5 \mathrm{kHz}$ ), were further amplified by Devices 3160 amplifier and then were rectified and smoothed (filter time constant $0.03 \mathrm{~s}$ ).

Each single movement was recorded on-line by a PDP 12 computer with a sampling rate of $250 \mathrm{~Hz}$ per channel. Signals were collected for $500 \mathrm{~ms}$ before and $500 \mathrm{~ms}$ after the onset of EMG activity in anterior deltoid. Fifteen to thirty movements were made by each subject against the two background forces of $12 \mathrm{~N}$ and $24 \mathrm{~N}$. Averaged records were aligned to the onset of EMG activity in the anterior deltoid.

In three control subjects and in two patients there was no anticipatory activity in TA when they stood normally on the floor. In these individuals, activity in TA was encouraged by making the subject unstable on a slight uphill slope (approximately $5^{\circ}$ ). In those with obvious anticipatory activity in TA, background activity in TS was encouraged, by leaning slightly forwards. However, a preceding silence in TS, as reported by Bouisset ${ }^{1}$ was seen in only three control subjects and in two patients.

\section{(C) Measurement of data}

The latency, amplitude and duration of the EMG bursts in each single record were measured using the computer display unit. A classical triphasic EMG burst pattern was usually seen in the deltoid muscle. EMG bursts in postural muscles were deemed to be significant if they occurred suddenly, were not part of ongoing tonic activity and were followed by an EMG silence. In some records there was no activity in certain postural muscles, while in others it was not possible to identify discrete bursts. The frequency with which obvious activity in postural muscles was absent was noted.

The latency of the bursts from each muscle was related to the onset of the anterior deltoid EMG. Bursts of activity in postural muscles which started $150 \mathrm{~ms}$ or more after the onset of anterior deltoid activity were disregarded. The amplitude of each EMG burst was measured by integrating the EMG record for the duration of the burst. Data from individual records have been averaged and mean values from each subject have been statistically analysed.

We shall refer to three subgroups of patients. The whole group studied after withdrawal of dopamine agonist therapy $(n=14)$, and those studied both ON and OFF therapy ( $=10)$. We have termed these: (1) "total patients OFF", (2) "paired patients ON" and (3) "paired patients OFF". Not all subjects performed both tasks. Of the nine "normal subjects", eight performed the $12 \mathrm{~N}$ task and nine the $24 \mathrm{~N}$ task. Of the fourteen "total patients OFF", 12 performed the $12 \mathrm{~N}$ task and 13 performed the $24 \mathrm{~N}$ task; however, of these only 11 performed both tasks. Of the 10 patients studied both OFF and ON, eight performed the $12 \mathrm{~N}$ task and nine performed the $24 \mathrm{~N}$ task; of these only seven performed both.

When comparing the amplitude and velocity of the arm movement in "normal subjects" and "total patients OFF" 
we have used unpaired Student's $t$ test for comparing the entire groups and have combined data from both tasks in an analysis of variance (ANOVA). To compare the amplitude and velocity of the arm movement in patients before and after levodopa therapy we have used paired $t$ tests at each load, and have combined data from both loads in an ANOVA for repeated measures. To compare latencies of the EMG bursts we have used Student's $t$ test and ANOVA as in the comparison of arm movement but when comparing the EMG activity (size and duration) of different groups we have used non-parametric statistics. In the comparison of the "paired patients OFF" with the "paired patients ON" the paired Wilcoxon test was used. For the analysis of the presence or absence of postural activity we have used the Chi squared test.

\section{Results}

All groups of subjects performed the task satisfactorily. Figure 1 illustrates typical responses obtained by averaging the signals from each trial at each of the two loads in one normal (fig 1, top) and one Parkinsonian subject OFF treatment (fig 1, bottom). Postural muscle activity was larger when movements were made against the larger load. Since there was a degree of variability in the timing and the size of responses from trial to trial, such averaged records highlight the earliest of a series of movements and reduce the apparent amplitude of EMG activity in all muscles. Accordingly, statistical analysis was performed on measurements of each individual trial.

\section{(1) Arm movement (table 2)}

Within any one of the groups of subjects ("normals", "total patients OFF", "paired patients ON", "paired patients OFF"), the average final distance moved by the arm was the same in both the $12 \mathrm{~N}$ and the $24 \mathrm{~N}$ tasks. Intergroup comparisons showed only one difference between the groups: movement amplitude in the $12 \mathrm{~N}$ task was slightly larger in the patients $\mathrm{ON}$ versus patients OFF (paired $t$ test, $\mathrm{p}<0.05$ ). Otherwise, the distance moved was the same for all tasks and all groups of subjects.

The velocity of arm movement in normals was faster in the $24 \mathrm{~N}$ than in the $12 \mathrm{~N}$ task $(\mathrm{p}<0.05$ paried $t$ test). However, although there was a tendency for the velocity of movement to be greater in the $24 \mathrm{~N}$ task than in the $12 \mathrm{~N}$ task in the three subgroups of patients, this did not reach statistical significance. The velocity of arm movement was slower in the "total patients OFF" group than in normal subjects for both the $12 \mathrm{~N}$ and the $24 \mathrm{~N}$ tasks ( $\mathrm{p}<0.05$ unpaired $t$ test for both). Levodopa increased the speed of patient's arm movement (ON versus OFF: ANOVAR using data from both $12 \mathrm{~N}$ and $24 \mathrm{~N}$ tasks: $\mathrm{p}<0.025 ; \mathrm{F}$ 7.44 ; df 1,6$)$ such that the "patients ON" were not statistically different from normal ( $p>0.05 ; \mathrm{F} 2 \cdot 17$, df 1,13$)$.

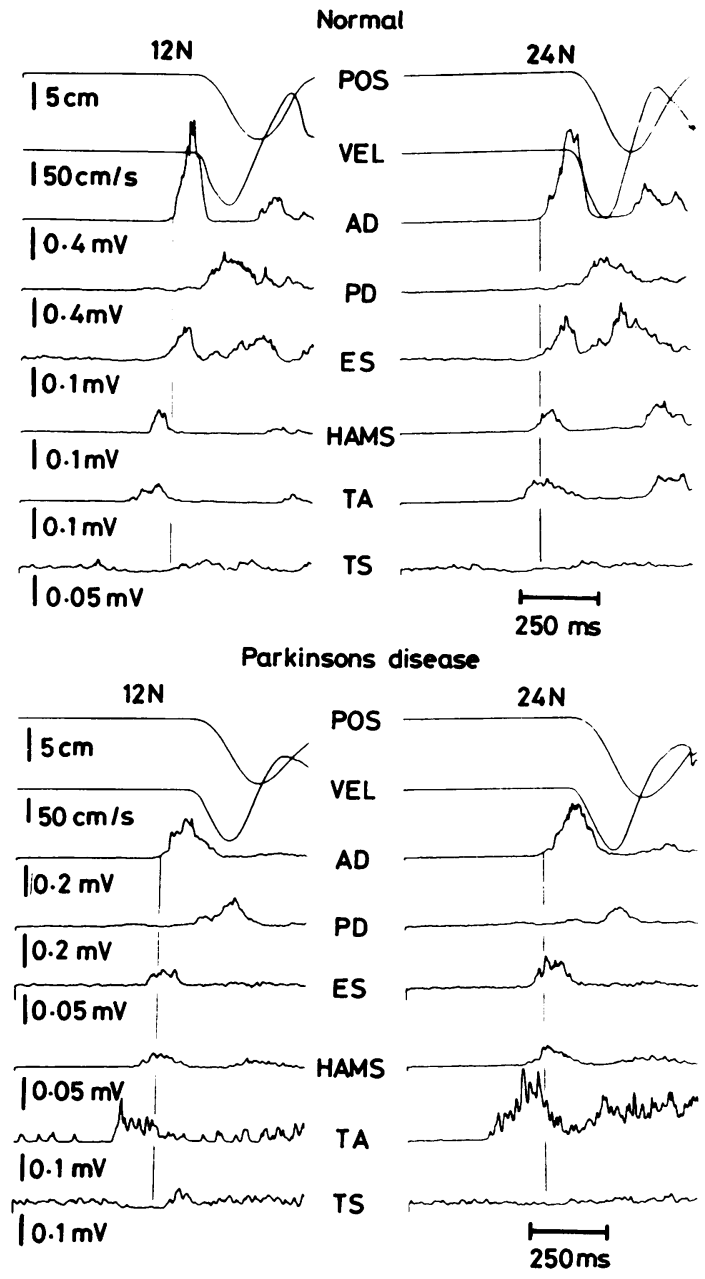

Fig 1 Averaged records from a normal subject (top) and a patient with Parkinson's disease OFF therapy (bottom). Arm position and velocity are plotted in the top records. Below these are rectified EMG traces from the prime mover agonist, anterior deltoid $(A D)$ and antagonist posterior deltoid $(P D)$, and from various ipsilateral postural muscles erector spinae (ES), biceps femoris (HAMS), tibialis anterior (TA) and triceps surae (TS). Records on the left are for the $12 \mathrm{~N}$ task and those on the right are for the $24 \mathrm{~N}$ task. The vertical lines in each record indicate the onset of activity in anterior deltoid. The records show that there is anticipatory activity in the postural muscles of both the normal and the Parkinsonian subject.

\section{(2) Prime mover agonist and antagonist EMG activity (table 2)}

In "normal subjects" and in "total patients OFF" the size but not the duration, of the first burst of agonist EMG activity (AG1) in anterior deltoid was larger in 
Table 2 The amplitude and velocity of arm movement $(A)$, and the size and duration $(B)$ of the integrated EMG burst in the prime mover (anterior deltoid) and the antagonist (posterior deltoid) in normal subjects and in patients with

Parkinson's disease

(A)

(1) Normal subjects

(2) Parkinson's disease

Total OFF

Paired OFF

Paired ON

(B)

Size (mV.ms)

(1) Normal subjects

(2) Parkinson's disease

Total OFF

Paired OFF

Paired ON

Duration (ms)

(1) Normal subjects

(2) Parkinson's disease

Total OFF

Paired OFF

Paired ON

Mean \pm 1 SEM shown

$\begin{array}{ll}\begin{array}{l}\text { Distance moved }(\mathrm{cm}) \\ 12 \mathrm{~N}\end{array} & 24 \mathrm{~N} \\ 14.8 \pm 0.7 & 15.8 \pm 0.9 \\ & \\ 14.0 \pm 0.8 & 15.4 \pm 0.8 \\ 14.7 \pm 1.2 & 16.2 \pm 1.2 \\ 17.0 \pm 0.9^{+} & 16.6 \pm 1.0\end{array}$

Anterior deltoid EMG

$12 \mathrm{~N} 24 \mathrm{~N}$

$16.4 \pm 4.7 \quad 20.2 \pm 4.9+$

$10 \cdot 9 \pm 1 \cdot 3$

$11 \cdot 7 \pm 2 \cdot 0$

$15 \cdot 4 \pm 2 \cdot 1^{++}$

$15 \cdot 6 \pm 2 \cdot 3 \dagger$

$16 \cdot 0 \pm 3 \cdot 1$

$20 \cdot 1 \pm 3 \cdot 8$

$121 \pm 7$

$129 \pm 12$

$122 \pm 9$

$123 \pm 13$

$132 \pm 13$

$141 \pm 14$

$146 \pm 19$

$139 \pm 13$

$\begin{array}{ll}\text { Arm } \begin{array}{c}\text { movement } \\ \text { Velocity }(\mathrm{cm} / \mathrm{s})\end{array} & \\ 12 \mathrm{~N} & 24 \mathrm{~N} \\ 134 \pm 10 & 145 \pm 14^{*} \\ 108.6^{\circ} & 116 \pm 6^{\circ} \\ 98 \pm 8 & 108 \pm 6 \\ 118 \pm 8^{+++} & 120 \pm 8^{+++}\end{array}$

EMG activity

Posterior deltoid EMG

$12 \mathrm{~N}$

$9 \cdot 6 \pm 2 \cdot 4$

$24 \mathrm{~N}$

$8.9 \pm 1.3$

$8.8 \pm 1.6$

$13 \cdot 0 \pm 2 \cdot 6$

$9 \cdot 7+1 \cdot 5$

$9 \cdot 1 \pm 1 \cdot 3$

$13.8 \pm 3.3$

$109 \pm 8$

$126 \pm 17$

$103 \pm 7$

$102 \pm 9$

$126 \pm 16^{++}$

$95+6$

$91 \pm 7$

$122 \pm 17$

Amongst the normal subjects, eight individuals were studied at $12 \mathrm{~N}$ and nine were studied at $24 \mathrm{~N}$. Amongst the total group of patients with Parkinson's disease, 12 were studied at $12 \mathrm{~N}$ and 13 were studied at $24 \mathrm{~N}$. Amongst the group of patients studied both ON and OFF, eight were studied at $12 \mathrm{~N}$ and nine were studied at $24 \mathrm{~N}$.

Comparison of $12 \mathrm{~N}$ vs $24 \mathrm{~N}$ task

*p $<0.05$ paired Student's $t$ test

tp $<0.05$ paired Wilcoxon

Comparison of "total patients OFF" vs "normals"

${ }^{\circ} p<0.05$ unpaired Student's $t$ test

Comparison of "paired patients OFF vs "paired patients ON"

$+p<0.05$ paired Student's $t$ test

$++\mathrm{p}<0.05$ paired Wilcoxon

$+++\mathrm{p}<0.05$ ANOVAR for repeated measures for both $12 \mathrm{~N}$ and $24 \mathrm{~N}$ results

movements made against the larger load $(\mathrm{p}<0.05$, Wilcoxon). There was a tendency for larger EMG bursts in the $24 \mathrm{~N}$ task compared with the $12 \mathrm{~N}$ task in the anterior deltoid for "paired patients OFF" and "paired patients ON" but this did not reach statistical significance ( $p>0.05$, Wilcoxon).

Differences in electrode placement and skin resistance make it difficult to compare absolute EMG amplitudes between different groups of patients. A more reliable comparison can be made between muscle activity in the same subject ON and OFF therapy. This showed an increase in the size, but not the duration, of AG1 in the "paired patients ON" for the $12 \mathrm{~N}$ task ( $\mathrm{p}<0.05$, Wilcoxon) but not for the $24 \mathrm{~N}$ task ( $p>0.05$, Wilcoxon).

The size, but not the duration, of the antagonist burst of EMG activity in posterior deltoid was larger in the $24 \mathrm{~N}$ than in the $12 \mathrm{~N}$ task in "normal subjects" (p < 0.05, Wilcoxon); however, there was no such difference in the three subgroups of patients $(p>$ 0.05 , Wilcoxon). Levodopa increased the duration of the antagonist burst in the $12 \mathrm{~N}$ task for the "patients ON" (p < 0.05, Wilcoxon) but not for the $24 \mathrm{~N}$ task (p > 0.05, Wilcoxon).
(3) Postural muscles

(a) Absence of postural responses (table 3). The majority of arm movements were accompanied in both normal and Parkinsonian subjects by EMG activity in all postural muscles studied (table $3 \mathrm{~A}$ ). However, there were occasions in subjects from both normal and patient groups when no detectable EMG activity occurred prior to that in the agonist muscle in one or more of the postural muscles recorded. These failures generally were more numerous both in "normal subjects" and in "total patients OFF", when they pulled against the smaller $(12 \mathrm{~N})$ load $(\mathrm{p}<0.01$ for ES and TA in "normal subjects") and $p<0.05$ for HAMS and TA in "total patients OFF"; Chi squared test). Apart from erector spinae in the $12 \mathrm{~N}$ task, patients had more failures than the normal subjects in all three postural muscles for both tasks $(p<0.05$, Chi squared test). The same pattern was seen in the patients studied both OFF and ON; when OFF, they had fewer postural responses than normal; when $O N$ the number of postural responses was close to normal.

Horak et $\mathrm{al}^{4}$ have found that postural muscle activity is enhanced during rapid arm movements. The velocity of arm movements tended to be slower in 
Table 3 (A) Frequency of postural responses in erector spinae (ES), hamstrings (HAMS) and tibialis anterior (TA) in the $12 \mathrm{~N}$ and $24 \mathrm{~N}$ tasks in normal subjects and in patients with Parkinson's disease. In $(B)$ the frequency of postural responses in tibialis anterior is plotted in relationship to the speed of arm movement.

(A)
i) Normal subjects
ii) Parkinson's disease
Total OFF
Paired OFF
Paired ON

(B)

Velocity $(\mathrm{cm} / \mathrm{sec})$

i) Normal subjects

ii) Parkinson's disease

Total OFF

\begin{tabular}{cccccc} 
& \multicolumn{5}{c}{ Postural responses/Total no. movements (\%) } \\
ES & & HAMS & $24 \mathrm{~N}$ & TA & \\
$12 \mathrm{~N}$ & $24 \mathrm{~N}$ & $12 \mathrm{~N}$ & $12 \mathrm{~N}$ & $24 \mathrm{~N}$ \\
$83 / 111(75)$ & $142 / 155(92)$ & $101 / 111(91)$ & $145 / 155(94)$ & $76 / 111(68)$ & $126 / 155(81)$ \\
& & & & & \\
$115 / 155(74)$ & $209 / 255(82)$ & $103 / 155(66)$ & $222 / 255(87)$ & $83 / 155(54)$ & $176 / 255(69)$ \\
$77 / 105(73)$ & $154 / 191(81)$ & $76 / 105(73)$ & $172 / 191(90)$ & $55 / 105(52)$ & $122 / 191(64)$ \\
$102 / 110(93)$ & $157 / 166(94)$ & $87 / 110(79)$ & $150 / 166(90)$ & $85 / 110(77)$ & $115 / 166(69)$
\end{tabular}

\begin{tabular}{cccccc}
\multicolumn{5}{c}{ Postural responses in tibialis anterior as a function of arm movement velocity } \\
$12 \mathrm{~N}$ & \multicolumn{5}{c}{$24 \mathrm{~N}$} \\
85 & $85-125$ & $>125$ & $<85$ & $85-125$ & $>125$ \\
$11 / 16(69)$ & $32 / 43(74)$ & $33 / 52(63)$ & $19 / 23(83)$ & $32 / 41(78)$ & $75 / 91(82)$ \\
$24 / 58(41)$ & $42 / 64(66)$ & $17 / 33(51)$ & $46 / 68(68)$ & $69 / 105(66)$ & $61 / 82(74)$
\end{tabular}

The number of subjects studied is as in table 2. The total number of records in which postural responses were evident is shown in relation to the number of trials undertaken (eq. 83/100), with the percentage of positive responses in parentheses.

patients with Parkinson's disease than in normal subjects (see table 2) which may have accounted for the difference in the number of postural responses between the two groups. To analyse this possibility in detail we measured those movements with velocities less than $85 \mathrm{~cm} / \mathrm{s}$, between $85-125 \mathrm{~cm} / \mathrm{s}$ and those greater than $125 \mathrm{~cm} / \mathrm{s}$ (table 3B). There are good $a$ priori reasons to suspect that activity in tibialis anterior is a major factor in the maintenance of equilibrium. If one considers the freely standing subject, with the knees locked, as an inverted pendulum pivoted at the ankles, ${ }^{7}$ then forward motion of the arm produces a reactive force on the body, causing it to tilt backwards. The force of this backward sway will be transmitted through the ankle to the tibialis anterior. Taking this into consideration, we have analysed the responses in tibialis anterior.

Normal subjects usually executed the arm movement with velocities greater than $85 \mathrm{~cm} / \mathrm{s}$. Patients with Parkinson's disease often executed the arm movement with a velocity less than $85 \mathrm{~cm} / \mathrm{s}$. However, even taking velocity into account, the number of postural responses remained less in the patients than in the normal subjects (table $3 \mathrm{~B}$ ).

(b) Latencies The time relationships between the onset of activity in different muscles are shown in fig 2 . The onsets of activity in postural muscles relative to that in anterior deltoid are plotted for "normal subjects" and for "total patients OFF" (fig 2, left) and for the same patients studied ON and OFF therapy (fig 2, right). Although there was a tendency for activity in the postural muscles to begin later relative to that of the agonist in the "total patients OFF" group compared with controls, and in those OFF treatment compared with those ON treatment, none of these differences achieved statistical significance $(p>0.05$, ANOVA combining data from all three muscles "nor- mal subjects" versus "total patients OFF" $-12 \mathrm{~N}: \mathrm{F}$ 0.57 , df 1, 17; 24 N: F 3.78, df 1, 17. "Paired patients OFF" versus "paired patients ON" $-12 \mathrm{~N}: \mathrm{F} 0 \cdot 42$, df $1,7 ; 24 \mathrm{~N}: \mathrm{F} 2 \cdot 63$, df 1,8$)$. Even the hamstrings latency in "total patients OFF", $(-23 \pm 9 \mathrm{~ms}$, at $12 \mathrm{~N}$ and $-28 \pm 11 \mathrm{~ms}$ at $24 \mathrm{~N}$ ) was not statistically different from the normal subjects $(-50 \pm 6 \mathrm{~ms}$ at $12 \mathrm{~N}$ and $-55 \pm 11 \mathrm{~ms}$ at $24 \mathrm{~N}$ ) in an unpaired Student's $t$ test or in an analysis of variance ( $p>0.05$, ANOVA combining data from both tasks, "total patients OFF" versus "normals": F 3.4, df 1, 17). In addition, the latency did not depend upon the size of the load in any group of subjects ( $p>0.05$, ANOVA combining data from all three muscles at each load).

(c) Amplitudes As previously stated, comparisons of absolute EMG size between different groups are unreliable so we have compared the size of EMG activity in the same subject $\mathrm{ON}$ and OFF therapy (fig 3). This showed that the size and duration of the first burst of EMG activity in erector spinae were no different for the $12 \mathrm{~N}$ or the $24 \mathrm{~N}$ tasks, nor were they increased after levodopa ( $p>0.05$, Wilcoxon).

For the hamstrings the size and duration of the first burst of EMG activity was greater in the $24 \mathrm{~N}$ task than in the $12 \mathrm{~N}$ task for the "paired patients OFF" ( $p<0.05$, Wilcoxon) but not for the "paired patients ON" ( $p>0.05$, Wilcoxon). After levodopa therapy there was no significant increase in the size or the duration of EMG activity for both tasks ( $p>0.05$, Wilcoxon).

For the tibialis anterior the duration but not the size of the first burst of EMG activity increased for the larger $(24 N)$ task in the "paired patients OFF" ( $p<$ 0.05 , Wilcoxon), but neither increased in the "paired patients ON" ( $p>0.05$, Wilcoxon). Levodopa caused an increase in both the size and the duration of EMG activity in tibialis anterior, and did so in both tasks (p 
$12 \mathrm{~N}$
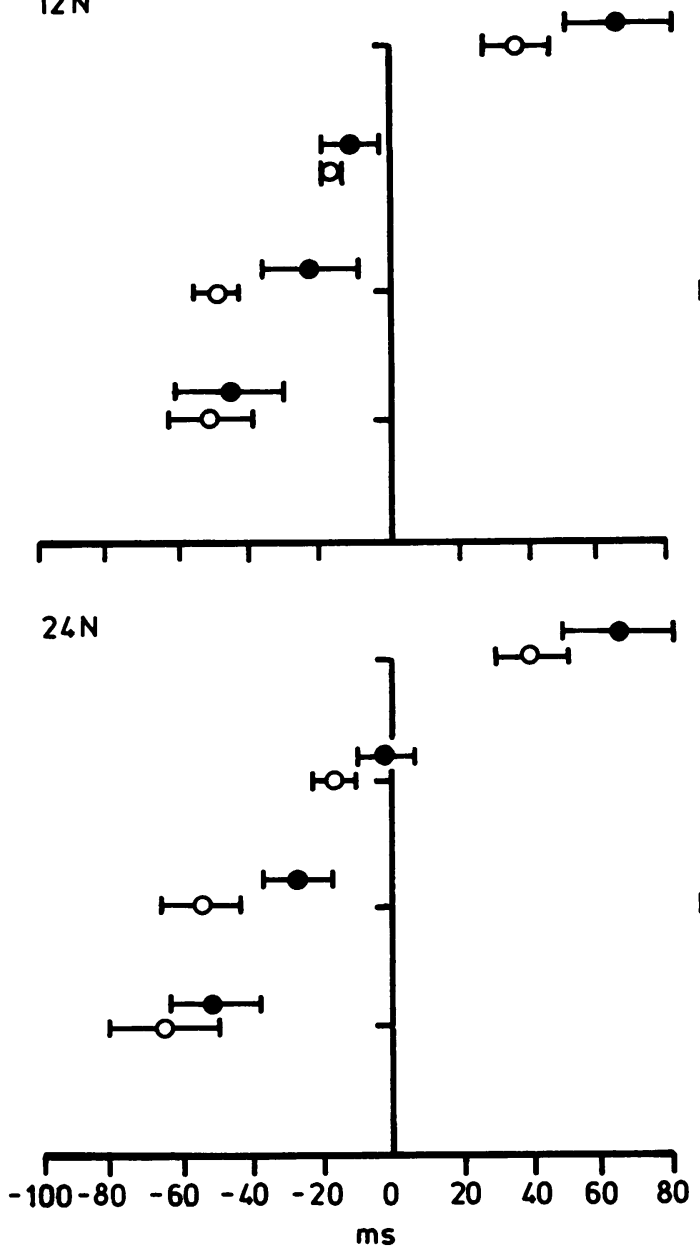

$12 N$

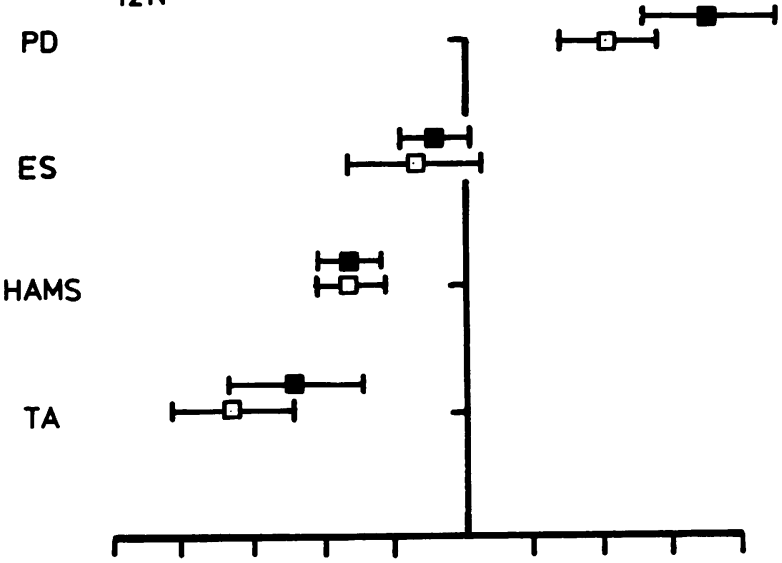

ES

HAMS

TA

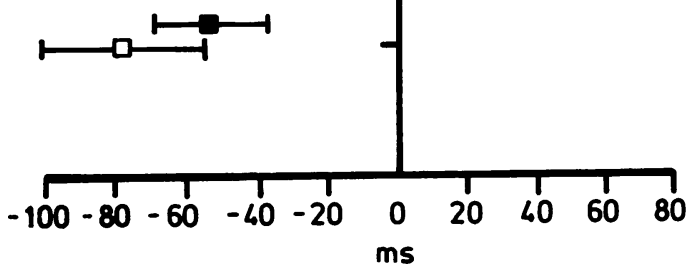

Fig 2 Mean latencies (with standard errors) of the onset of EMG bursts in posterior deltoid (PD) and associated postural responses in erector spinae (ES), biceps femoris (HAMS) and tibialis anterior (TA) relative to the onset of activity in the anterior deltoid (shown at time 0 ). Panels on the left show the normal group (open symbols) and the total group of Parkinsonian patients, (closed symbols); panels on the right show data for those patients who were studied both ON (open symbols) and OFF treatment (closed symbols). The upper panels show data for the $12 \mathrm{~N}$ task and the lower panels show data for the $24 N$ task. There was no significant difference between the latencies of any of the postural muscles in any group.

$<0.05$, Wilcoxon). Two striking examples of the difference in EMG activity of patients with Parkinson's disease OFF and ON therapy are shown in fig 4.

\section{Discussion}

These data suggest that, for voluntary forward flexion of the arm, (1) patients with Parkinson's disease deliver instructions to their postural muscles at the right time, relative to the onset of activity in the prime mover, but (2) the amount of activity is less than normal (the latter conclusion is based on the comparison of EMG activity in postural muscles in patients studied ON and OFF treatment, and on the reduced number of responses in postural muscles in patients compared with controls). These conclusions are particularly appropriate to data derived from the tibialis anterior, which for reasons argued earlier, 

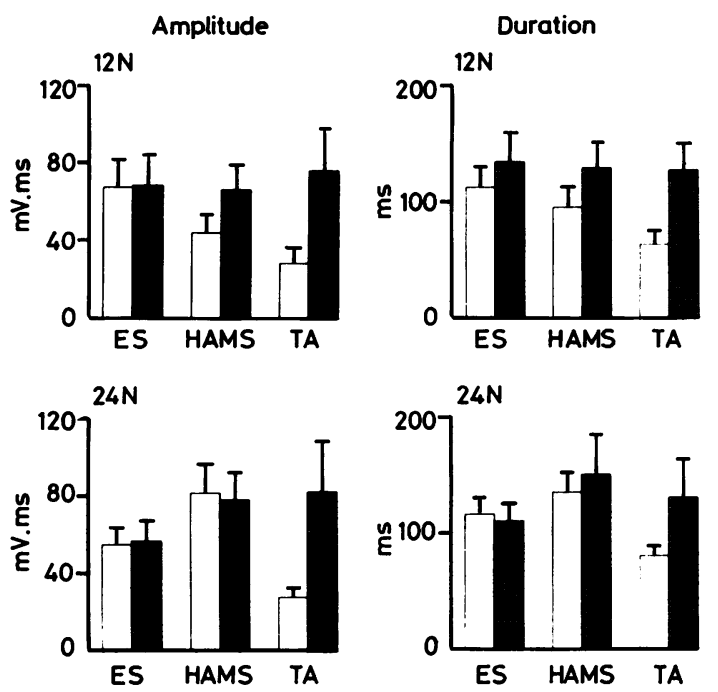

Fig 3 Size (mV.ms, left) and duration (ms, right) for patients studied $O N$ (filled bars) and OFF therapy (open bars). Mean and standard errors are shown. The three pairs of bars represent the three postural muscles measured (ES-left, HAMS-middle and TA-right). Upper panels show data for the $12 \mathrm{~N}$ task and lower panels show data for the $24 N$ task. There is a significant increase in size and duration of EMG activity in TA after levodopa $(p<0.05$, Wilcoxon).

bears the brunt of anticipatory postural correction in this task.

Our findings differ from those of Bouisset, ${ }^{36}$ who found a delay in the onset of postural muscle activity, as compared with normals when patients with Parkinson's disease raised their arms. However, they did not study tibialis anterior and their conclusions were based on mechanical records of leg movement. ${ }^{6}$ We have shown that postural responses, although present at the correct time, are smaller in patients than normals, so may not have contributed as much to mechanical changes.

Another point of interest in our study was that the patients with Parkinson's disease activated the three postural muscles studied (erector spinae, hamstrings and tibialis anterior) in the same temporal sequence as normal subjects. Accordingly, we conclude that patients with Parkinson's disease deliver the complete program for forward flexion of the arm, with its associated postural activity, with correct timing but reduced activity in the initial EMG bursts. In other words, the form of the complete program seems preserved in Parkinson's disease but its content is reduced.

This raises the possibility of whether the reduced activity in the postural muscles of patients with Par-

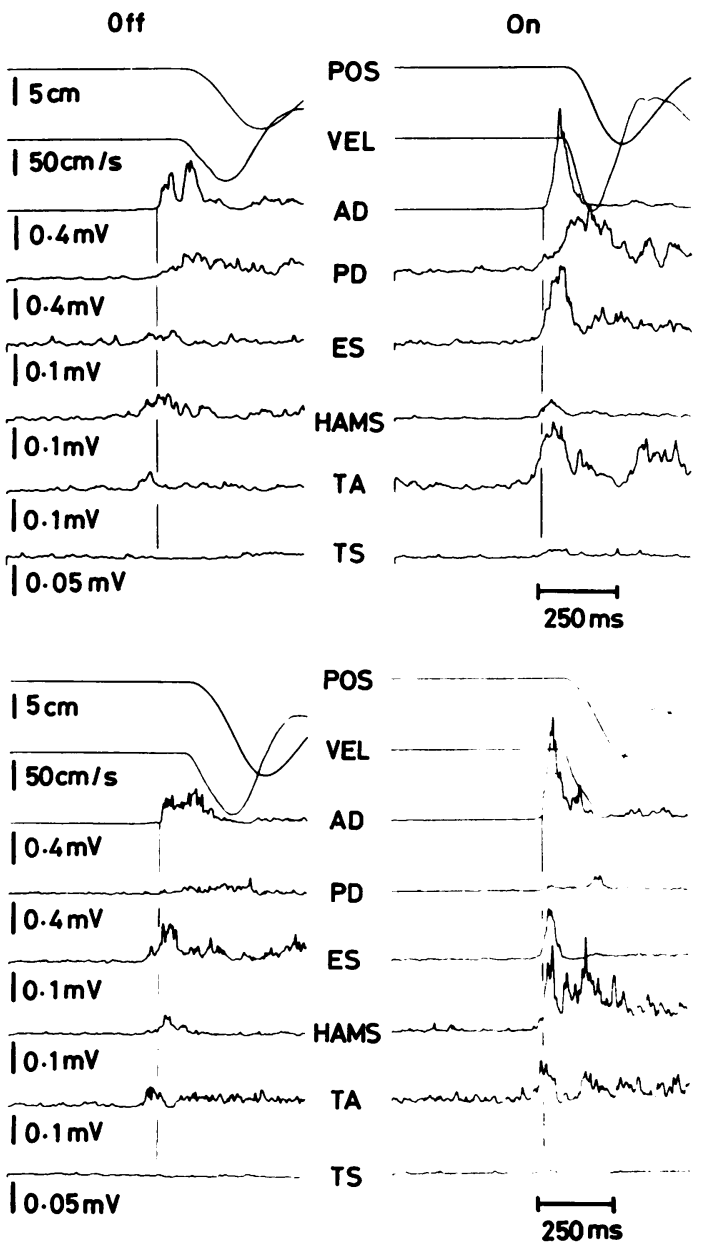

Fig 4 Averaged records from two patients with Parkinson's disease. Arm position and velocity are plotted in the top records. Below these are rectified EMG traces from the prime mover agonist anterior deltoid $(A D)$ and antagonist posterior deltoid (PD) and from various ipsilateral postural muscles erector spinae (ES), hamstrings (HAMS), tibialis anterior (TA) and triceps surae (TS). Records on the left (OFF) were before therapy and those on the right (ON) were after therapy. The EMG activity in the postural muscles is greater after levodopa but its time of onset does not change.

kinson's disease is appropriate to their reduced velocity of movement. Since the activity in the prime mover, and the resulting velocity of arm movement, tended to be reduced in the patients with Parkinson's disease, it could be argued that the reduced postural activity in the present task was appropriate to the activity in the prime mover. This question can only be established by measurement of reactive forces and 
body sway and by comparison of these with the anticipatory postural muscle activity. A further study along these lines is required to settle this point.

In conclusion, the results suggest that the patients with Parkinson's disease produce feedforward adjustments of posture at the right time, but whether they are of appropriate size remains to be determined, although we can say that no patient fell over when undertaking the task studied.

Our thanks are due to the patients who agreed to be withdrawn temporarily from their normal drug therapy and to Mr H C Bertoya and Mr R Miller for expert technical assistance. The work was funded by the research funds of the Bethlem and Maudsley Hospitals and by the Medical Research Council. JCR is a Royal Society Research Fellow.

\section{References}

1 Bouisset S, Zattara M. A sequence of postural adjustments precedes voluntary movement. Neurosci Lett 1981;22:287-302.
2 Traub MM, Rothwell JC, Marsden CD. Anticipatory postural responses in Parkinson's disease and other akinetic rigid syndromes and in cerebellar ataxia. Brain 1980;103:393-412.

3 Bazalgette D, Zattara M, Bouisset S, Bathien N, Rondot P. Postural adjustments associated with rapid voluntary arm movements in Parkinson's disease. In: Proceedings of VIII International Symposium on Parkinson's disease. Advances in Neurology 1986;45:371-4.

4 Horak FB, Esselman P, Anderson ME, Lynch MK. The effects of movement velocity, mass displaced, and task certainty on associated postural adjustments made by normal and hemiplegic subjects. $J$ Neurol Neurosurg Psychiatry 1984;47:1020-8.

5 Freidl WG, Hallett M, Simon SR. Postural adjustments associated with rapid voluntary arm movements. 1 . Electromyographic data. J Neurol Neurosurg Psychiatry 1984;47:611-22.

6 Bazalgette D, Zattara M, Bathien N, Bouisset S, Rondot $\mathrm{P}$. Adjustments posturaux associes au mouvement rapide du bras dans la maladie de parkinson. J Biophysique et Biomechanique 1985;9:396-7.

7 Cordo PJ, Nashner LM. Properties of postural adjustments associated with rapid arm movements. $J$ Neurophysiol 1982;3:423-35. 